\title{
Effect of Administering Lactobacillus Culture Isolated from Ensiled Hymenache acutigluma via Drinking Water on Meat and Egg Quality of Pegagan Ducks
}

\author{
Fitra $\operatorname{Yosi}^{1}{ }^{1}$, Nuni Gofar ${ }^{2}$, Eli Sahara ${ }^{1}$, Sofia Sandi ${ }^{1}$, Meisji Liana Sari ${ }^{1}$, Farin Farandhita ${ }^{1}$, and Hendy Yodhistira ${ }^{1}$ \\ ${ }^{I}$ Department of Animal Science, Faculty of Agriculture, University of Sriwijaya, Indralaya 30662, South Sumatra, Indonesia \\ ${ }^{2}$ Department of Soil Science, Faculty of Agriculture, University of Sriwijaya, Indralaya 30662, South Sumatra, Indonesia \\ *Corresponding author's Email: fitrayosi@ unsri.ac.id ; ORCID: 0000-0001-9550-6474
}

Received: 13 October 2021

Accepted: 30 November 2021

\begin{abstract}
Lactobacillus spp. is one of the lactic acid bacteria, has a positive effect on improving the meat and egg quality in poultry. However, there is a paucity of information about the effect of Lactobacillus culture isolated from ensiled swamp grass on meat and egg characteristics. The present study aimed to investigate the effect of supplementing Lactobacillus culture isolated from ensiled Hymenache acutigluma (LHA) via drinking water on the duck meat and egg quality. A total of 60 Pegagan ducks aged 24-week-old were used in the current study and kept for 60 days. Ducks were randomly allocated into 5 treatment groups and 4 replicates per group, consisting of LHA 0 (control group without LHA solution), LHA 1, LHA 2, LHA 3, and LHA 4 (treatment groups supplemented with LHA solutions in drinking water with concentrations of $10^{6}, 10^{7}, 10^{8}$, and $10^{9} \mathrm{CFU} / \mathrm{ml}$, respectively). The results showed that the value of cooking loss linearly increased, followed by a linear decrease in the water holding capacity after LHA addition. However, there was no change in the meat $\mathrm{pH}$ and moisture content. Further measurements revealed that both the yolk height and yolk index were linearly improved after being administered with LHA solutions, but no difference was found in other egg variables, including the yolk weight, diameter, and color, albumen weight, and height, as well as the eggshell weight and thickness. In conclusion, the provision of LHA via drinking water with a concentration of up to $10^{9} \mathrm{CFU} / \mathrm{ml}$ could modulate the meat and egg quality of ducks. The LHA solutions enhanced the ability of meat protein to bind water, thereby inhibiting nutrient loss. Moreover, LHA had a greater effect on improving yolk quality, compared to albumen and eggshell.
\end{abstract}

Keywords: Drinking water, Egg quality, Ensiled Hymenache acutigluma, Lactobacillus, Meat, Pegagan ducks

\section{INTRODUCTION}

As one of the lactic acid bacteria, Lactobacillus spp. is the most commonly used probiotics for poultry and has a positive impact on the growth performance of ducks, such as increasing body weight and egg production, improving feed intake, and reducing feed conversion (Hassan and Komilus, 2020; Khattab et al., 2021). These benefits are supported by the main ability of Lactobacillus spp. in repressing the colonization and proliferation of various pathogenic bacteria in the digestive tract (Wang et al., 2018; Bae et al., 2020), thereby creating a healthy and optimally functioning intestine. Due to these benefits, many studies have been conducted on isolating Lactobacillus bacteria from various sources, such as the gastrointestinal tract (Kamollerd et al., 2016; Pokorná et al., 2019) and fermented foods or dairy products (Caggia et al., 2015; Rao et al., 2015; Xu et al., 2020). However, the use of Lactobacillus cultures isolated from ensiled swamp forage is still limited and has not been investigated so far.

In a previous study, several isolates derived from the silage of Hymenache acutigluma, which is one of the swamp forages that grow in the swamplands of South Sumatra, Indonesia, have been successfully cultured (Sandi et al., 2018). All isolates obtained from this ensilage belong to the genus Lactobacillus which is highly resistant to acidity conditions, both at low and high $\mathrm{pH}$ (Sandi et al., 2019). Based on the previous investigation, it was identified that the oral supplementation of Lactobacillus isolated from ensiled Hymenache acutigluma (LHA) has a positive outcome on improving 
the relative weight and length of internal organs and lowering lipids in duck serum (Yosi et al., 2020).

In addition to improving the growth performance of poultry, growing evidence has verified that administration of Lactobacillus strains could improve meat quality, such as maintaining $\mathrm{pH}$, increasing water holding capacity, and reducing cooking loss (Wang et al., 2019; Dev et al., 2020). Some investigations also reported that not only meat quality but also egg quality could be modulated by the administration of Lactobacillus cultures, such as egg weight, yolk and albumen indices, shell thickness, Haugh unit, and yolk color (Gallazzi et al., 2008; Siadati et al., 2018). Since the relationship between LHA supplementation and poultry product quality has not been investigated so far, there is a need to conduct further examination addressing the effect of LHA on modulating meat and egg properties. As limited information is available on ducks, therefore, Pegagan ducks, known as a local duck from South Sumatra, Indonesia, were used in the current study

\section{MATERIALS AND METHODS}

\section{Ethical approval}

This experiment was performed in accordance with regulation 18/2015 on livestock, animal health and welfare in Indonesia, and ethical standards at Sriwijaya University, South Sumatra, Indonesia.

\section{Experimental design}

After an adaptation period of 3 days, a total of sixty 24-week-old Pegagan ducks, which was a local duck obtained from a duck farmer in Indralaya Regency, South Sumatra, Indonesia, were randomly distributed into 20 plots and reared for 60 days. The treatments consisted of 5 groups and 4 replicates for each group by supplementing LHA solutions with increasing concentrations, namely: LHA 0 (control group without LHA), LHA 1, LHA 2, LHA 3, and LHA 4 (LHA groups with a concentration of $10^{6}, 10^{7}, 10^{8}$, and $10^{9} \mathrm{CFU} / \mathrm{ml}$, respectively). Determination of LHA concentration referred to the number of Lactobacillus occupying the gastrointestinal tract of broiler chickens, which ranged from $10^{6}$ to $10^{9}$ CFU/g contents (Rehman et al., 2007). The LHA solutions were delivered via drinking water during the first 30 days of the experimental period with an amount of 10 $\mathrm{ml} / \mathrm{bird} / \mathrm{day}$. The diet was formulated to meet or exceed nutrients for egg-type ducks in the laying period according to Indonesian National Standard and administered ad libitum throughout the experiment. The composition of nutrients and ingredients of the experimental diet is presented in Table 1.

\section{Preparation of ensiled Hymenache acutigluma}

The process of making Hymenache acutigluma silage followed the procedure as described by the previous study (Yosi et al., 2020). The initial stage was cutting the fresh grass into smaller pieces of about $2-5 \mathrm{~cm}$, followed by the withering process by storing it at $27-30^{\circ} \mathrm{C}$ and not being exposed to direct sunlight for at least 24 hours. A total of $500 \mathrm{~g}$ of withered grass was mixed with molasses and water $(0.3 \%$ of the grass's dried weight), then put in a three-layer plastic bag under anaerobic conditions and stored at room temperature for 21 days.

\section{Preparation of LHA solutions}

The detailed stages of preparation of the LHA solutions and determination of their concentrations were as described by Yosi et al. (2020) with modification. Lactobacillus isolates were first incubated for 48 hours at $37^{\circ} \mathrm{C}$, which had previously been cultured in deMan Rogosa Sharpe broth (Sandi et al., 2018). After that, the isolates were mixed with peptone solution replacing $0.85 \% \mathrm{NaCl}$ solution, homogenized, and compared with McFarland standard solution to determine the concentration of LHA solutions based on the level of turbidity.

Table 1. Nutrient composition and ingredients of the experimental diet for Pegagan laying ducks for 2 months

\begin{tabular}{lc}
\hline Ingredients & Composition (\%) \\
\hline Corn meal & 16 \\
Dried noodle waste meal $^{\text {Concentrate }}{ }^{\mathrm{a}}$ & 40 \\
Bran $^{\mathrm{b}}$ & 32 \\
Premix & 10 \\
Methionine & 1.0 \\
Lysine & 0.6 \\
Total & 0.4 \\
Calculated nutrient content & \\
$\quad$ Metabolizable energy (Kcal/kg) & 100 \\
$\quad$ Crude protein (\%) & 3007.2 \\
$\quad$ Crude fiber (\%) & 18.74 \\
$\quad$ Calcium (\%) & 4.60 \\
$\quad$ Available phosphorus (\%) & 4.22 \\
\hline
\end{tabular}

a : A mixture of fish meal, soybean meal, coconut meal, meat and bone meal, wheat flakes, peanut meal, canola, leaf meal, vitamins, calcium, phosphate, and trace minerals. ${ }^{\mathrm{b}}$ : Provided per kilogram of diet, including Calcium (32.5\%), Phosphor (1\%), Iron (6 g), Manganese ( $4 \mathrm{~g})$, Iodine (0.075 g), Copper (0.3 g), Zinc (3.75 g), Vitamin B12 (0.5 mg), and Vitamin D3 $(50,000,000 \mathrm{IU}){ }^{c}$ : Calculated according to the recommendation of the Indonesian National Standard. 


\section{Meat quality analysis}

After 2 months of rearing, one 32-week-old duck from each replicate was selected to measure meat quality, which included $\mathrm{pH}$, water holding capacity (WHC), cooking loss (CL), and moisture content (MC). Measurement of $\mathrm{pH}, \mathrm{WHC}$, and $\mathrm{CL}$ followed the procedure as described by Yosi and Sandi (2014), while MC was analyzed according to the procedure of AOAC (2000). The $\mathrm{pH}$ value was observed 24 hours after slaughter, which was previously stored at $-4{ }^{\circ} \mathrm{C}$ (Lan et al., 2017). After being mashed with a meat grinder, $2 \mathrm{~g}$ of breast meat samples were weighed and dissolved in $18 \mathrm{ml}$ distilled water until homogeneous. After completely dissolved, the solution was filtered and then measured using a pH meter (pHep Hanna 98107) that had previously been calibrated with standard solutions of 4 and 7 . Before measuring CL, $20 \mathrm{~g}$ sample of breast meat was weighed and then put into polyethylene plastic. After being sealed with a vacuum pack, the samples were cooked in a water bath at $80^{\circ} \mathrm{C}$ for 30 minutes and then cooled at room temperature $\left(25-27^{\circ} \mathrm{C}\right)$. The meat surface was dried with filter paper and its weight was measured using an analytical balance (Yosi and Sandi, 2014). Once recorded, the CL was calculated by dividing the weight loss during cooking by the weight of fresh meat and expressed in percentage. To measure MC, $1 \mathrm{~g}$ of breast meat was weighed and dried using an oven at $100-105^{\circ} \mathrm{C}$ until its weight was constant. For the WHC, $0.3 \mathrm{~g}$ of meat was first placed on Whatman 41 filter paper and then pressed between 2 metal plates with a load of $35 \mathrm{~kg}$ for 5 minutes. The wet area was determined by subtracting the total area with the area covered by the meat sample (Yosi and Sandi, 2014).

\section{Egg quality measurements}

After supplementing with LHA solutions in drinking water for 30 days, 2 eggs per replicate were randomly selected for measurements of the quality of yolk, albumen, and shell. The process of measuring egg variables was the same as described by Yosi et al. (2016). Each sample egg was weighed with a digital scale (Metler AE100-0.001) and recorded. The yolk and albumen were separated using an egg separator and weighed. The shell weight was calculated by subtracting yolk and albumen from the whole egg weight. Albumen and yolk height were determined with a tripod micrometer, while yolk diameter and albumen length and width were measured using a caliper. The shell thickness was calculated from the average measurement at the top, bottom, and center of the shell, which was measured using a micrometer screw gauge. Determination of yolk color was performed by comparing the Roche color fan with the color of each yolk. The yolk and albumen indices and Haught unit were calculated referring to Yosi et al. (2019) as follows: Yolk index $=$ yolk height/yolk diameter, while Albumen index = albumen height/average of albumen length and width. The Haugh unit was obtained with the calculation: $\mathrm{HU}=100$ $\log \left(\mathrm{H}+7.57-1.7 \mathrm{~W}^{0.37}\right)$, where $\mathrm{W}$ and $\mathrm{H}$ are egg weight (g) and thick albumen height $(\mathrm{mm})$, respectively.

\section{Statistical analysis}

All experimental data were analyzed using SPSS statistical software (IBM SPSS version 26). The data were subjected to one-way ANOVA. In case of a significant effect on the meat and egg quality parameters, Duncan's multiple comparison test was used to find out the differences between the treatment groups. In addition, the orthogonal comparison was performed with polynomial regression to determine the linear, quadratic, and cubic effects of increasing concentration of LHA supplementation via drinking water. After analysis, the data were presented in tables as means with pooled standard error of the mean (SEM). P $<0.05$ was considered as a statistical difference.

\section{RESULTS}

\section{Effects on meat quality}

In the current study, meat quality covering $\mathrm{pH}$, WHC, MC, and CL was measured and the results were presented in Table 2. The present findings revealed that the CL and WHC of breast meat were significantly influenced by treatments $(\mathrm{p}<0.05)$, but no changes were identified in the meat $\mathrm{pH}$ and $\mathrm{MC}$ after consuming LHA in drinking water $(p>0.05)$. Furthermore, there was a linear decrease in meat $\mathrm{CL}$ and an increase in WHC at the same time after LHA addition. Both the control and LHA groups with a concentration up to $10^{8} \mathrm{CFU} / \mathrm{ml} \mathrm{did}$ not exhibit any difference in the value of CL $(p>0.05)$. However, it then declined after the administration of LHA solution with a concentration of $10^{9} \mathrm{CFU} / \mathrm{ml}(\mathrm{p}<0.05)$. In contrast to WHC, where it started increasing after the addition of LHA with a concentration of $10^{7} \mathrm{CFU} / \mathrm{ml}$ compared to the control group $(\mathrm{p}<0.05)$.

\section{Effects on egg quality}

Based on the analysis of the yolk parameters presented in Table 3, it was confirmed that simply the 
height of the yolk linearly improved with the LHA addition ( $p<0.05$ ), while no alterations were found in the weight, diameter, and color of the yolk. Insignificant differences between treatment groups were also identified in the albumen and eggshell parameters, including albumen and shell weight, albumen height, and shell thickness $(p>0.05)$. Furthermore, some calculations presented that LHA supplementation in drinking water noticeably elevated the yolk index $(\mathrm{p}<0.05)$, but no effect $(p>0.05)$ was detected on the albumen index and Haugh unit of duck eggs (Graph 1). A significant improvement in yolk index occurred after the administration of LHA solution with a concentration of $10^{8} \mathrm{CFU} / \mathrm{ml}$ and above in drinking water, compared to the control group ( $\mathrm{p}<0.05)$.

\section{DISCUSSION}

The value of $\mathrm{pH}$ plays a crucial role in meat quality (Yosi and Sandi, 2014). The non-significant influence on the breast meat $\mathrm{pH}$ has also occurred as reported by Chen et al. (2018) with applying Lactobacillus rhamnosus strain $\mathrm{CF}$ (Cheng $\mathrm{Fu}$ ) in the White Leghorns chicken diet. Similarly, other investigations that apply different genus of bacteria, such as Bacillus coagulans, Bacillus subtilis fmbJ, and Enterococcus faecium also reported no different results on meat pH (Zhou et al., 2010; Bai et al., 2017; Lan et al., 2017). However, studies conducted either by Abdulla et al. (2017) or Atela et al. (2019) confirmed that the $\mathrm{pH}$ of the breast meat in broiler chickens markedly changed after supplementation with Bacillus subtilis DSM 17299 or multi-strain bacteria. These results showed that variations in using bacterial species/strains as probiotics or experimental design might be the main factor in determining the meat $\mathrm{pH}$ changes in poultry (Popova, 2017). Further, the meat MC after LHA supplementation was not different from that of the control. This finding is in line with studies by Abdulla et al. (2017) and Zhou et al. (2010) in which Bacillus subtilis DSM 17299 and Bacillus coagulans ZJU0616 were implemented as probiotics in feed, respectively, where the MC of breast muscle of chicken did not alter by treatment groups.

The WHC and CL are important indicators that are interrelated and commonly used in defining meat quality (Mohammed et al., 2021). A decrease in meat CL followed by improvement in WHC has a positive effect on meat quality (Yosi and Sandi, 2014). The present results were also in agreement with the study by Zheng et al. (2014) who reported that the administration of Enterococcus faecium notably improved WHC and reduced CL in the broiler chickens' breast meat. Likewise, Abou-Kassem et al. (2021) also recorded that there was a decrease in the CL and increase in WHC in meats of 42day growing Japanese quails after supplementing Bacillus toyonensi and Bifidobacterium bifidum in the diet. It was verified that the improved meat WHC after probiotic addition in the diet was highly regulated by the presence of muscle protein (Zheng et al., 2014), pointing that the administering of LHA also might have a major effect on the abundance of meat proteins which then contribute to enhanced water holding capacity in duck meat. In addition, it is also presumed that LHA might affect the intramuscular fat content and polyunsaturated fatty acids composition of duck's breast meat. According to the previous study, the improved meat quality after consuming Clostridium butyricum was associated with the changes in the meat fatty acid composition, such as n-3 and n-6 polyunsaturated fatty acids (Yang et al., 2010). However, this assumption needs to be examined through further investigation by measuring the fatty acid composition in the duck meat.

Table 2. Meat quality of Pegagan laying ducks after consuming Lactobacillus isolated from ensiled Hymenache acutigluma via drinking water for 30 days

\begin{tabular}{|c|c|c|c|c|c|c|c|c|c|}
\hline \multirow{2}{*}{ Item } & \multicolumn{5}{|c|}{ Groups of LHA } & \multirow{2}{*}{ SEM } & \multicolumn{3}{|c|}{$p$ value } \\
\hline & LHA 0 & LHA 1 & LHA 2 & LHA 3 & LHA 4 & & Linear & Quadratic & Cubic \\
\hline $\mathrm{pH}$ & 5.73 & 5.63 & 5.65 & 5.75 & 5.70 & 0.09 & 0.721 & 0.484 & 0.202 \\
\hline Cooking loss (\%) & $32.79^{\mathrm{a}}$ & $33.86^{\mathrm{a}}$ & $30.88^{\mathrm{ab}}$ & $31.7^{\mathrm{ab}}$ & $28.78^{\mathrm{b}}$ & 1.48 & 0.008 & 0.304 & 0.922 \\
\hline Moisture content (\%) & 74.63 & 74.83 & 76.07 & 74.23 & 75.80 & 0.78 & 0.338 & 0.869 & 0.193 \\
\hline Water holding capacity (\%) & $37.58^{\mathrm{b}}$ & $40.81^{\mathrm{ab}}$ & $43.13^{\mathrm{a}}$ & $43.49^{\mathrm{a}}$ & $42.84^{\mathrm{a}}$ & 1.77 & 0.005 & 0.057 & 0.980 \\
\hline
\end{tabular}

LHA: Lactobacillus solutions isolated from ensiled Hymenache acutigluma, SEM: Standard error of the mean, ${ }^{\mathrm{a}, \mathrm{b}}$ different superscripts in the same row mean significant difference ( $<<0.05$ ). LHA 0: Control group, LHA $1,2,3$, and 4: LHA groups with a concentration of $10^{6}, 10^{7}$, $10^{8}$, and $10^{9} \mathrm{CFU} / \mathrm{ml}$, respectively. 
Table 3. Egg quality of Pegagan laying ducks after consuming Lactobacillus isolated from ensiled Hymenache acutigluma via drinking water for 30 days

\begin{tabular}{|c|c|c|c|c|c|c|c|c|c|}
\hline \multirow{2}{*}{ Item } & \multicolumn{5}{|c|}{ Groups of LHA } & \multirow{2}{*}{ SEM } & \multicolumn{3}{|c|}{ p value } \\
\hline & LHA 0 & LHA 1 & LHA 2 & LHA 3 & LHA 4 & & Linear & Quadratic & Cubic \\
\hline \multicolumn{10}{|l|}{ Yolk } \\
\hline Weight (g) & 20.97 & 20.63 & 20.49 & 20.35 & 20.41 & 0.55 & 0.265 & 0.593 & 0.997 \\
\hline Diameter $(\mathrm{cm})$ & 4.53 & 4.36 & 4.54 & 4.18 & 4.36 & 0.15 & 0.146 & 0.687 & 0.535 \\
\hline Height $(\mathrm{cm})$ & $1.58^{\mathrm{b}}$ & $1.65^{\mathrm{ab}}$ & $1.78^{\mathrm{ab}}$ & $1.73^{\mathrm{ab}}$ & $1.88^{\mathrm{a}}$ & 0.11 & 0.009 & 1.000 & 0.499 \\
\hline Color & 13.25 & 14.00 & 13.50 & 14.00 & 13.75 & 0.28 & 0.142 & 0.210 & 0.451 \\
\hline \multicolumn{10}{|l|}{ Albumen } \\
\hline Weight (g) & 39.93 & 41.39 & 43.28 & 39.92 & 37.52 & 2.34 & 0.248 & 0.054 & 0.919 \\
\hline Height $(\mathrm{cm})$ & 0.78 & 0.75 & 0.73 & 0.74 & 0.73 & 0.06 & 0.384 & 0.680 & 0.845 \\
\hline \multicolumn{10}{|l|}{ Shell } \\
\hline Weight (g) & 4.43 & 4.60 & 4.81 & 4.43 & 4.17 & 0.22 & 0.183 & 0.068 & 0.895 \\
\hline Thickness $(\mathrm{mm})$ & 0.36 & 0.39 & 0.34 & 0.38 & 0.37 & 0.03 & 0.808 & 0.791 & 0.580 \\
\hline
\end{tabular}

LHA: Lactobacillus solutions isolated from ensiled Hymenache acutigluma, SEM: Standard error of mean, ${ }^{\mathrm{a}, \mathrm{b}}$ different superscripts in the same row mean significant difference between treatment groups ( $<$ 0.05). LHA 0: Control group, LHA 1, 2, 3, and 4: LHA groups with a concentration of $10^{6}, 10^{7}, 10^{8}$ and $10^{9} \mathrm{CFU} / \mathrm{ml}$, respectively.

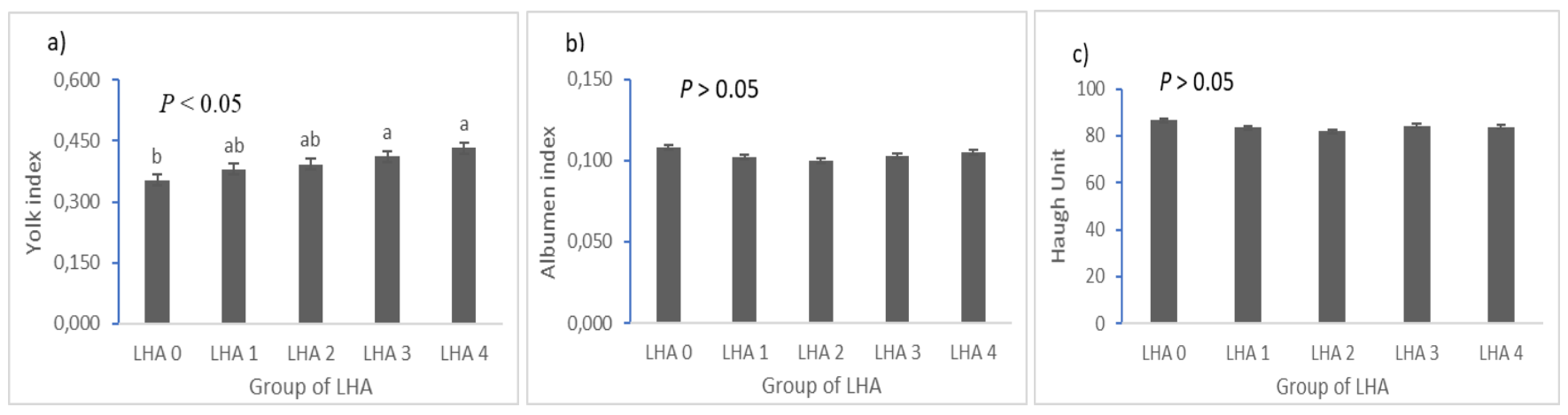

Graph 1. Yolk index (a), albumen index (b), and Haugh unit (c) of Pegagan duck after supplementing with Lactobacillus isolated from ensiled Hymenache acutigluma (LHA) via drinking water for 30 days. LHA 0: Control group, LHA 1, 2, 3, and 4: LHA groups with a concentration of $10^{6}, 10^{7}, 10^{8}$ and $10^{9} \mathrm{CFU} / \mathrm{ml}$, respectively. The different letters $(\mathrm{a}, \mathrm{b})$ above the column mean significant difference (p < $0.05)$.

The internal and external quality of eggs can be evaluated from the parameters of the yolk, albumen, and eggshell properties (Rath et al., 2015). After administering LHA solutions via drinking water for 1 month, most of the egg parameters measured in this study were not altered, except the yolk height and index were notably improved. Kalavathy et al. (2005) and Siadati et al. (2018) also reported that no improvement was recorded in yolk parameters, including yolk color and weight, after applying Lactobacillus strains either in the laying hens or quails diet. A slightly different outcome was presented by Forte et al. (2016), where there was a meaningful change in the yolk color after being enriched with Lactobacillus acidophilus and Bacillus subtilis in the diet of laying hen.

Concerning the physical quality of albumen, several studies recorded that there were variations in poultry responses after Lactobacillus supplementation. The insignificant results of albumen parameters in this study were also in compliance with the investigation by Saksrithai and King (2020), confirming that albumen height and Haugh unit of laying hens aged 58 to 60 weeks did not differ between control and treatment groups with adding Lactobacillus culture into drinking water. Similarly, Forte et al. (2016) also reported that laying hens supplied with dietary Lactobacillus acidophilus and Bacillus subtilis exhibited no change in the weight and percentage of albumen and Haugh units. On the opposite, some studies have demonstrated a positive effect of supplementing Lactobacillus in enhancing albumen quality. Gallazzi et al. (2008) affirmed that the application of Lactobacillus acidophilus D2/CSL as probiotics was proven to increase Haugh unit in laying hens. This is also 
in line with Siadati et al. (2018) that the provision of native Lactobacillus strains had positive effects on albumen height and the Haugh unit in Japanese quails. For eggshell parameters, the results from the current study are also supported by other studies, where no effect was obtained either on shell weight or shell thickness by the inclusion of Lactobacillus acidophilus D2/CSL or Enterococcus faecalis (Gallazzi et al., 2008; Zhang et al., 2019). In reverse, a study by Panda et al. (2008) identified a significant increase in shell thickness after consuming Lactobacillus sporogenes in the feed. Besides Lactobacillus, the provision of Pediococcus acidilactici also provided beneficial outcomes for increasing eggshell thickness in laying hens (Mikulski et al., 2012). Based on this observation, it is assumed that the varied effects of bacteria as probiotics on egg quality might be influenced by the type and the administration method of the bacteria.

\section{CONCLUSION}

In conclusion, the provision of Lactobacillus culture isolated from ensiled Hymenache acutigluma (LHA) via drinking water with a concentration of up to $10^{9} \mathrm{CFU} / \mathrm{ml}$ could modulate the meat and egg quality of Pegagan ducks. The LHA solutions might enhance the ability of meat protein to bind to water, thereby inhibiting nutrient loss. Moreover, LHA had a greater effect on improving yolk quality compared to albumen and eggshell.

\section{DECLARATIONS}

\section{Competing interests}

All authors involved in this research work declare having no competing interests

\section{Authors' contributions}

FY conceptualized the research work, collected and analyzed the sample, processed and interpreted the data, and wrote the initial manuscript. NG and SS participated in drafting the research plan. ES and MLS were involved in the analysis and interpretation of the data. FF and HY conducted animal trials, collected and analyzed samples in the laboratory. All authors revised and approved the final version of the manuscript.

\section{Acknowledgments}

The authors would like to thank the University of Sriwijaya, in particular the Institute for Research and Community Services, which has facilitated this research work and supported research funds through the Professional Grant in 2018 with the contract number: 0109.26/UN9/SB3.LP2M.PT/2018.

\section{Ethical considerations}

All related to ethical issues, consisting of plagiarism, consent to publish, misconduct, data fabrication and/or falsification, double publication and/or submission, and redundancy, have been checked by the authors.

\section{REFERENCES}

Abdulla NR, Zamri ANM, Sabow AB, Kareem KY, Nurhazirah S, Ling FH, Sazili AQ, and Loh TC (2017). Physicochemical properties of breast muscle in broiler chickens fed probiotics, antibiotics or antibiotic-probiotic mix. Journal of Applied Animal Research, 45(1): 64-70. DOI: https://www.doi.org/10.1080/09712119.2015.1124330

Abou-Kassem DE, Elsadek MF, Abdel-Moneim AE, Mahgoub SA, Elaraby GM, Taha AE, Elshafie MM, Alkhawtani DM, Abd El-Hack ME and Ashour EA (2021). Growth, carcass characteristics, meat quality, and microbial aspects of growing quail fed diets enriched with two different types of probiotics (Bacillus toyonensis and Bifidobacterium bifidum). Poultry Science, 100(1): 84-93. DOI: https://www.doi.org/10.1016/j.psj.2020.04.019

Association of Official Analytical Chemists (AOAC) (2000). Official Methods of Analysis, 17th Edition. Washington D.C. Available at: https://pdf.wecabrio.com/aoac-officialmethods-of-analysis-17th-ed.pdf

Atela JA, Mlambo V, and Mnisi CM (2019). A multi-strain probiotic administered via drinking water enhances feed conversion efficiency and meat quality traits in indigenous chickens. Animal Nutrition, 5(2): 179-184. DOI: https://www.doi.org/10.1016/j.aninu.2018.08.002

Bae D, Kim DH, Chon JW, Song KY, and Seo KH (2020). Synergistic effects of the early administration of Lactobacillus kefiranofaciens DN1 and Kluyveromyces marxianus KU140723-05 on the inhibition of Salmonella Enteritidis colonization in young chickens. Poultry Science, 99(11): 5999-6006. DOI: https://www.doi.org/10.1016/j.psj.2020.07.032

Bai K, Huang Q, Zhang J, He J, Zhang L, and Wang T (2017). Supplemental effects of probiotic Bacillus subtilis fmbJ on growth performance, antioxidant capacity, and meat quality of broiler chickens. Poultry Science, 96(1): 74-82. DOI: https://www.doi.org/10.3382/ps/pew246

Caggia C, De Angelis M, Pitino I, Pino A, and Randazzo CL (2015). Probiotic features of Lactobacillus strains isolated from Ragusano and Pecorino Siciliano cheeses. Food Microbiology, 50: 109-117. DOI: https://www.doi.org/10.1016/j.fm.2015.03.010

Chen F, Gao SS, Zhu LQ, Qin SY, and Qiu HL (2018). Effects of dietary Lactobacillus rhamnosus CF supplementation on growth, meat quality, and microenvironment in specific pathogen-free chickens. Poultry Science, 97(1): 118-123. DOI: https://www.doi.org/10.3382/ps/pex261

Dev K, Mir NA, Biswas A, Kannoujia J, Begum J, Kant R, and Mandal A (2020). Dietary synbiotic supplementation improves the growth performance, body antioxidant pool, serum biochemistry, meat quality, and lipid oxidative stability in broiler chickens. Animal Nutrition, 6(3): 325332. DOI: https://www.doi.org/10.1016/j.aninu.2020.03.002

Forte C, Moscati L, Acuti G, Mugnai C, Franciosini MP, Costarelli S, Cobellis G, and Trabalza-Marinucci M (2016). Effects of dietary Lactobacillus acidophilus and Bacillus 
subtilis on laying performance, egg quality, blood biochemistry and immune response of organic laying hens. Journal of Animal Physiology and Animal Nutrition, 100(5): $\quad$ 977-987.

DOI: https://www.doi.org/10.1111/jpn.12408

Gallazzi D, Giardini A, Mangiagalli MG, Marelli S, Ferrazzi V, Orsi C, and Cavalchini LG (2008). Effects of Lactobacillus acidophilus D2/CSL on laying hen performance. Italian Journal of Animal Science, 7(1): 27-37. DOI: https://www.doi.org/10.4081/ijas.2008.27

Hassan N, and Komilus C (2020). Effects of probiotic (Lactobacillus spp) mixed with cassava leaves (Manihot esculenta) on growth performances and meat quality of Cherry Valley duck (Anas platyrhynchos domesticus). Journal of Agrobiotechnology, 11: 32-45. DOI: https://www.doi.org/10.37231/jab.2020.11.1s.232

Kalavathy R, Abdullah N, Jalaludin S, Wong CMVL, and Ho YW (2005). Effects of Lactobacillus cultures on performance and egg quality during the early laying period of hens. Journal of Animal and Feed Sciences, 14(3): 537547. DOI: https://www.doi.org/10.22358/jafs/67121/2005

Kamollerd C, Surachon P, Maunglai P, Siripornadulsil W, and Sukon P (2016). Assessment of probiotic potential of Lactobacillus reuteri MD5-2 isolated from ceca of Muscovy ducks. Korean Journal of Veterinary Research, 56(1): 1-7. DOI: https://www.doi.org/10.14405/kjvr.2016.56.1.1

Khattab AAA, El Basuini, MFM, El-Ratel IT, and Fouda SF (2021). Dietary probiotics as a strategy for improving growth performance, intestinal efficacy, immunity, and antioxidant capacity of white Pekin ducks fed with different levels of CP. Poultry Science, 100(3): 1-13. DOI: https://www.doi.org/10.1016/j.psj.2020.11.067

Lan RX, Lee SI, and Kim IH (2017). Effects of Enterococcus faecium SLB 120 on growth performance, blood parameters, relative organ weight, breast muscle meat quality, excreta microbiota shedding, and noxious gas emission in broilers. Poultry Science, 96(9): 3246-3253. DOI: https://www.doi.org/10.3382/ps/pex101

Mikulski D, Jankowski J, Naczmanski J, Mikulska M, and Demey V (2012). Effects of dietary probiotic (Pediococcus acidilactici) supplementation on performance, nutrient digestibility, egg traits, egg yolk cholesterol, and fatty acid profile in laying hens. Poultry Science, 91(10): 2691-2700. DOI: https://www.doi.org/10.3382/ps.2012-02370

Mohammed AA, Zaki RS, Negm EA, Mahmoud MA, and Cheng HW (2021). Effects of dietary supplementation of a probiotic (Bacillus subtilis) on bone mass and meat quality of broiler chickens. Poultry Science, 100(3): 1-11. DOI: https://www.doi.org/10.1016/j.psj.2020.11.073

Panda AK, Rao SSR, Raju MVLN, and Sharma SS (2008). Effect of probiotic (Lactobacillus sporogenes) feeding on egg production and quality, yolk cholesterol and humoral immune response of White Leghorn layer breeders. Journal of the Science of Food and Agriculture, 88(1): 43-47. DOI: https://www.doi.org/10.1002/jsfa.2921

Pokorná A, Maňáková T, and Č́žek A (2019). Properties of potentially probiotic Lactobacillus isolates from poultry intestines. Acta Veterinaria Brno, 88: 73-84. DOI: https://www.doi.org/10.2754/avb20198801073

Popova T (2017). Effect of probiotics in poultry for improving meat quality. Current Opinion in Food Science, 14: 72-77. DOI: https://www.doi.org/10.1016/j.cofs.2017.01.008
Rao K, Chennappa G, Suraj U, Nagaraja H, Raj APC, and Sreenivasa MY (2015). Probiotic potential of Lactobacillus strains isolated from Sorghum-based traditional fermented food. Probiotics and Antimicrobial Proteins, 7(2): 146-156. DOI: https://www.doi.org/10.1007/s12602-015-9186-6

Rath PK, Mishra PK, Mallick BK, and Behura NC (2015). Evaluation of different egg quality traits and interpretation of their mode of inheritance in White Leghorns. Veterinary World, 8(4): 449-452. DOI: https://www.doi.org/10.14202/vetworld.2015.449-452

Rehman HU, Vahjen W, Awad WA, and Zentek J (2007). Indigenous bacteria and bacterial metabolic products in the gastrointestinal tract of broiler chickens. Archives of Animal Nutrition, 61(5): 319-335. DOI: https://www.doi.org/10.1080/17450390701556817

Saksrithai K, and King AJ (2020). Lactobacillus species in drinking water had no main effects on sulphur compounds from manure, egg quality, and selected serum parameters of second cycle hens. British Poultry Science, 61(3): 328-335. DOI: https://www.doi.org/10.1080/00071668.2019.1709618

Sandi S, Miksusanti M, Sari ML, Sahara E, Supriyadi A, Gofar N, and Asmak A (2019). Acid resistance test of probiotic isolated from silage forage swamp on in vitro digestive tract. Indonesian Journal of Fundamental and Applied $\begin{array}{llll}\text { Chemistry, } & 4(1) \text { : } & \text { 15-19. }\end{array}$ https://www.doi.org/10.24845/ijfac.v4.i1.15

Sandi S, Yosi F, Sari ML, and Gofar N (2018). The characteristics and potential of lactic acid bacteria as probiotics in silage made from Hymenachne acutigluma and Neptunia oleracea lour. E3S Web of Conferences, 68: 1-4. DOI: https://www.doi.org/10.1051/e3sconf/20186801017

Siadati SA, Ebrahimnezhad Y, Jouzani GS, and Shayegh J (2018). Evaluation of the probiotic potential of some native Lactobacillus strains on the laying performance and egg quality parameters of Japanese quails. Iranian Journal of Applied Animal Science, 8(4): 703-712. DOI: https://www.doi.org/10.1590/1806-9061-2016-0393

Wang L, Feng Y, Zhang X, and Wu G (2019). Effect of probiotic Lactobacillus reuteri $\mathrm{XC} 1$ coexpressing endoglucanase and phytase on intestinal $\mathrm{pH}$ and morphology, carcass characteristics, meat quality, and serum biochemical indexes of broiler chickens. Revista Brasileira de Zootecnia, 48: 111. DOI: https://www.doi.org/10.1590/RBZ4820180273

Wang L, Li L, Lv Y, Chen Q, Feng J, and Zhao X (2018). Lactobacillus plantarum restores intestinal permeability disrupted by Salmonella infection in newly-hatched chicks. Scientific Reports, 8(1): 1-10. DOI: https://www.doi.org/10.1038/s41598-018-20752-Z

Xu Y, Zhou T, Tang H, Li X, Chen Y, Zhang L, and Zhang J (2020). Probiotic potential and amylolytic properties of lactic acid bacteria isolated from Chinese fermented cereal foods. Food Control, 111: 1-7. DOI: https://www.doi.org/10.1016/j.foodcont.2019.107057

Yang X, Zhang B, Guo Y, Jiao P, and Long F (2010). Effects of dietary lipids and Clostridium butyricum on fat deposition and meat quality of broiler chickens. Poultry Science, 89(2): 254-260. DOI: https://www.doi.org/10.3382/ps.2009-00234

Yosi F, Hidayah N, Jurlinda, and Sari ML (2016). The physical quality of salted Pegagan duck egg using palm oil fronds ash and liquid smoke as a curing agent. Buletin Peternakan, 40(1): 66-74. DOI: https://www.doi.org/10.21059/buletinpeternak.v40i1.8886 
Yosi F, and Sandi S (2014). Meat quality, blood profile, and fecal ammonia concentration of broiler supplemented with liquid smoke. Media Peternakan, 37(3): 169-174. DOI: https://www.doi.org/10.5398/medpet.2014.37.3.169

Yosi F, Sandi S, Gofar N, Sari ML, and Sahara E (2020). Supplementation of lactic acid bacteria derived from ensiled kumpai tembaga on live body weight, gastrointestinal tract, internal organs, and blood profiles in Pegagan ducks. Advances in Animal and Veterinary Sciences, 8(9): 916924.

DOI: https://www.doi.org/10.17582/journal.aavs/2020/8.9.916.92 $\underline{4}$

Yosi F, Wahyuni D, Riswandi, Herasti F, Lestari IA, and Makinudin (2019). The physicochemical and microbiological quality of Pegagan duck eggs immersed with Duku fruit peel solution in different storage period. Buletin Peternakan, 43(2): 141-146. DOI: https://www.doi.org/10.21059/buletinpeternak.v43i2.41279
Zhang Y, Ma W, Zhang Z, Liu F, Wang J, Yin Y, and Wang Z (2019). Effects of Enterococcus faecalis on egg production, egg quality and caecal microbiota of hens during the late laying period. Archives of Animal Nutrition, 73(3): 208221.

DOI: https://www.doi.org/10.1080/1745039X.2019.1591128

Zheng A, Luo J, Meng K, Li J, Zhang S, Li K, Liu G, Cai H, Bryden WL, and Yao B (2014). Proteome changes underpin improved meat quality and yield of chickens (Gallus gallus) fed the probiotic Enterococcus faecium. BMC Genomics, 15(1): 1-14. DOI: https://www.doi.org/10.1186/1471-2164$15-1167$

Zhou X, Wang Y, Gu Q, and Li W (2010). Effect of dietary probiotic, Bacillus coagulans, on growth performance, chemical composition, and meat quality of Guangxi Yellow chicken. Poultry Science, 89(3): 588-593. DOI: https://www.doi.org/10.3382/ps.2009-00319 